\title{
Infrared Induced Reactivity on the Surface of Isolated Size-Selected Clusters: Dissociation of $\mathrm{N}_{2} \mathrm{O}$ on Rhodium Clusters
}

\author{
Suzanne M. Hamilton, ${ }^{\dagger}$ W. Scott Hopkins, ${ }^{\dagger}$ Dan J. Harding, ${ }^{\ddagger, \S}$ Tiffany R. Walsh, ${ }^{\ddagger}$ Philipp Gruene, ${ }^{\S}$ \\ Marko Haertelt, ${ }^{\S}$ André Fielicke, ${ }^{\S}$ Gerard Meijer, ${ }^{\S}$ and Stuart R. Mackenzie ${ }^{\star,+}$ \\ Department of Chemistry, University of Oxford, Physical and Theoretical Chemistry Laboratory, South Parks Road, \\ Oxford, OX1 3QZ U.K., Department of Chemistry and Centre for Scientific Computing, University of Warwick, Coventry, \\ CV4 7AL, U.K., and Fritz-Haber-Institut der Max-Planck-Gesellschaft, Faradayweg 4-6, D-14195 Berlin, Germany
}

Received September 4, 2009; E-mail: stuart.mackenzie@chem.ox.ac.uk; fielicke@fhi-berlin.mpg.de

Infrared multiple photon dissociation spectroscopy (IR-MPD) has recently emerged as a powerful technique in determining the structures of small gas-phase transition metal clusters. A form of indirect or action spectroscopy, IR-MPD relies on the loss of some moiety from the cluster to serve as a mass-spectrometric signature that infrared radiation has been absorbed. Monitoring either the depletion of the parent cluster signal or the enhancement of the fragment signal as a function of wavelength provides a highly sensitive method by which to record the vibrational spectrum of naked and/or decorated metal clusters.

Most IR-MPD studies on naked and decorated transition metal clusters to date have concentrated on the mid-IR region, exciting either the vibrations of molecules adsorbed on the cluster surface ${ }^{1}$ or metal-oxygen stretches. ${ }^{2}$ More recently, the implementation of the inert messenger technique, ${ }^{3}$ in combination with the intense radiation from a free-electron laser (FEL), has extended IR-MPD spectroscopy into the far-infrared. This allows the metal-metal modes to be probed directly thereby yielding more direct structural information on the metal framework itself. ${ }^{4,5}$

Here, we present evidence of infrared driven surface chemistry on $\mathrm{Rh}_{n} \mathrm{~N}_{2} \mathrm{O}^{+}$clusters. IR-pumping of any vibrational mode of a molecularly adsorbed $\mathrm{N}_{2} \mathrm{O}$ molecule results in the dissociation of the adsorbate with the concomitant loss of $\mathrm{N}_{2}$ and the production of a partially oxidized rhodium cluster.

All experiments were performed at the Free Electron Laser for Infrared eXperiments (FELIX) facility in The Netherlands, and the details of the experiment have been published previously. ${ }^{4}$ Briefly, as implemented here, rhodium clusters are generated by laser ablation of a rotating rhodium rod in the presence of a helium carrier gas doped with argon $(0.1-0.3 \%)$. Nitrous oxide was admitted, post ablation, via a late mixing nozzle, and the resulting gas mix was allowed to equilibrate in a cryogenically cooled copper channel $(173 \mathrm{~K})$ before expansion into vacuum to form a molecular beam. The cluster beam, containing a range of naked and decorated clusters, both neutral and charged, is intersected by the counter propagating FELIX beam in front of the source region of a reflectron time-of-flight mass spectrometer. Whenever the IR frequency is in resonance with an IR active mode of a species in the molecular beam, that species may absorb photons, heat up, and can eventually fragment. The experiment runs at $10 \mathrm{~Hz}$ with the IR radiation present every other cycle. Comparison of the mass spectra of the cationic species present recorded with and without the FELIX beam as a function of the IR wavelength yields depletion/enhancement spectra reflecting infrared absorption and subsequent processes. Spectra are recorded between 100 and $2350 \mathrm{~cm}^{-1}$, covering the

\footnotetext{
University of Oxford.

University of Oxford.
University of Warwick.

\$ Fritz-Haber-Institut, Berlin.
}

range of ligand vibrations as well as of the internal modes of the metal cluster. The former comprise the subject of the present communication.

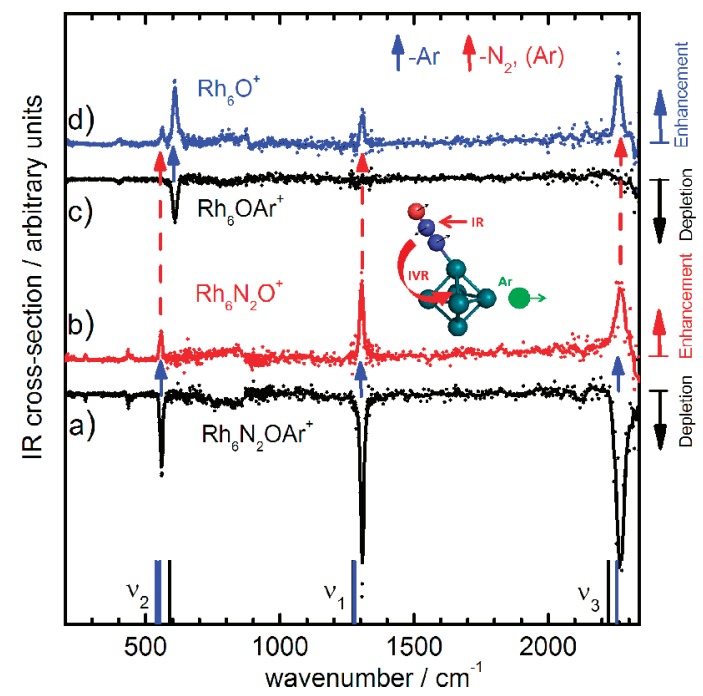

Figure 1. (a) IR-MPD depletion spectra of $\mathrm{Rh}_{6} \mathrm{~N}_{2} \mathrm{OAr}^{+}$and (b) the resulting enhancement in the $\mathrm{Rh}_{6} \mathrm{~N}_{2} \mathrm{O}^{+}$signal. The close correlation with the $\mathrm{N}_{2} \mathrm{O}$ mode wavenumbers (black bars for free $\mathrm{N}_{2} \mathrm{O}$, blue bars calculated for the complex) confirms the molecular nature of the adsorption. (c) IR-MPD spectrum of $\mathrm{Rh}_{6} \mathrm{OAr}^{+}$. (d) The spectrum in the $\mathrm{Rh}_{6} \mathrm{O}^{+}$channel shows clear enhancement at wavenumbers corresponding to excitation of $\mathrm{Rh}_{6} \mathrm{~N}_{2} \mathrm{O}^{+}$ modes indicating infrared driven cluster surface chemistry.

Figure $1 \mathrm{a}$ and $\mathrm{b}$ show the IR-MPD spectrum of $\mathrm{Rh}_{6} \mathrm{~N}_{2} \mathrm{OAr}^{+}$ complexes in the region of the free $\mathrm{N}_{2} \mathrm{O}$ normal modes. Pumping each $\mathrm{N}_{2} \mathrm{O}$ mode results in strong depletion of the Ar-tagged complexes and corresponding enhancement in the $\mathrm{Rh}_{6} \mathrm{~N}_{2} \mathrm{O}^{+}$signal, reflecting intramolecular vibrational redistribution (IVR) and the subsequent evaporation of the physisorbed argon atoms,

$$
\mathrm{Rh}_{6} \mathrm{~N}_{2} \mathrm{OAr}_{m}^{+}+x h v \rightarrow \mathrm{Rh}_{6} \mathrm{~N}_{2} \mathrm{O}^{+}+m \mathrm{Ar}
$$

The correlation of the depletion/enhancement signals with the known normal modes of free $\mathrm{N}_{2} \mathrm{O}$, ${ }^{6}$ as well as with the calculated vibrational wavenumbers for the $\mathrm{Rh}_{6} \mathrm{~N}_{2} \mathrm{O}^{+}$complex (see Supporting Information), represents clear evidence of the molecular nature of the $\mathrm{N}_{2} \mathrm{O}$ adsorption. This, itself, is somewhat surprising as $\mathrm{N}_{2} \mathrm{O}$ binds molecularly to extended crystalline rhodium surfaces only at low temperature with temperature controlled desorption experiments showing it to decompose as low as $95 \mathrm{~K}$ on $\mathrm{Rh}(110){ }^{7}$ The temperature of the clusters in this study can be assumed to be close to that of the cluster channel, i.e., ca. $173 \mathrm{~K}$. Under single collision conditions, however, cationic rhodium 
clusters react with nitrous oxide solely to yield sequential oxide clusters with accompanying $\mathrm{N}_{2}$ release. $^{8}$

In all of our spectra, $v_{1}$ and $v_{3}$, the two stretches, at $1305 \mathrm{~cm}^{-1}$ and $2270 \mathrm{~cm}^{-1}$, are observed slightly blue-shifted compared with free $\mathrm{N}_{2} \mathrm{O}$ (by $c a .34$ and $46 \mathrm{~cm}^{-1}$, respectively) while the bending mode, $v_{2}$, at $560 \mathrm{~cm}^{-1}$, is red-shifted by $c a .30 \mathrm{~cm}^{-1}$. These shifts agree well with those calculated for the N-bound, $\left[\mathrm{ONN}-\mathrm{Rh}_{6}\right]^{+}$ complex using density functional theory (blue bars in Figure 1; see the Supporting Information for details). We are unaware of any IR spectroscopy of $\mathrm{N}_{2} \mathrm{O}$ on extended rhodium surfaces, but these spectral shifts are consistent with those for nitrogen-bound $\mathrm{N}_{2} \mathrm{O}$ on $\mathrm{Pd}(110)$ by reflection-absorption infrared spectroscopy ${ }^{9}$ and on $\mathrm{Pt}(111)$ and $\mathrm{Ru}(001)$ by electron energy loss spectroscopy. ${ }^{10} \mathrm{In}$ a recent matrix isolation infrared study, the $\mathrm{N}-\mathrm{O}$ stretching mode of the N-bound Rh-NNO molecule was observed at $1200.6 \mathrm{~cm}^{-1} .^{11}$

In addition to the IVR-Ar-loss channel identified above, we have also observed a cluster surface reaction channel for a range of sizes $n=4-8$. Figure $1 \mathrm{~d}$ shows the spectrum observed in the $\mathrm{Rh}_{6} \mathrm{O}^{+}$ channel in the same spectral region. The major features in the production spectrum of $\mathrm{Rh}_{6} \mathrm{O}^{+}$can be identified as originating from absorption by a larger cluster complex. The $610 \mathrm{~cm}^{-1}$ peak is the expected enhancement arising from the IR-MPD of $\mathrm{Rh}_{6} \mathrm{OAr}_{m}{ }^{+}$in the region of the metal-oxygen stretch (Figure 1c),

$$
\mathrm{Rh}_{6} \mathrm{OAr}_{m}^{+}+x h v \rightarrow \mathrm{Rh}_{6} \mathrm{O}^{+}+m \mathrm{Ar}
$$

More intriguingly, however, clear increases in the $\mathrm{Rh}_{6} \mathrm{O}^{+}$cluster signal is observed upon pumping of each of the $\mathrm{N}_{2} \mathrm{O}$ normal modes in $\mathrm{Rh}_{6} \mathrm{~N}_{2} \mathrm{OAr}_{m}{ }^{+}(m=0,1,2)$. On the basis of a detailed analysis matching absolute depletions with corresponding enhancements, we can eliminate the possibility that these signals arise from the loss of $\mathrm{N}_{2} \mathrm{O}$ and $\mathrm{Ar}$ from $\mathrm{Rh}_{6} \mathrm{O}\left(\mathrm{N}_{2} \mathrm{O}\right) \mathrm{Ar}_{m}{ }^{+}$clusters (see Supporting Information). Instead, they arise from a reactive channel involving dissociation of the surface bound $\mathrm{N}_{2} \mathrm{O}$ with the subsequent loss of molecular nitrogen;

$$
\mathrm{Rh}_{6} \mathrm{~N}_{2} \mathrm{OAr}_{m}^{+}+x h v \rightarrow\left[\mathrm{Rh}_{6} \mathrm{~N}_{2} \mathrm{OAr}_{m}^{+}\right]^{*} \rightarrow \mathrm{Rh}_{6} \mathrm{O}^{+}+\mathrm{N}_{2}, m \mathrm{Ar}
$$

In other words, vibrational pumping of the molecularly adsorbed $\mathrm{N}_{2} \mathrm{O}$ results in sufficient heating of the cluster to promote the system over the barrier to dissociative adsorption. If the original $\mathrm{N}_{2} \mathrm{O}$ is, as the spectroscopy suggests, bound to the cluster via the extreme $\mathrm{N}$ atom, this channel represents a significant structural rearrangement as the $\mathrm{O}$ atom swings around ending up bound to the metal cluster as the $\mathrm{N}_{2}$ departs. We calculate the binding energy of $\mathrm{N}_{2} \mathrm{O}$ on $\mathrm{Rh}_{6}{ }^{+}$to be $0.78 \mathrm{eV}$ which represents an upper limit for the barrier to dissociation as otherwise only molecular desorption would occur. Calculations performed at the density functional level of theory, using a hybrid functional, have identified several plausible reaction pathways (see Supporting Information).

A detailed study of the various absolute signal depletions and enhancements for $\mathrm{Rh}_{6} \mathrm{~N}_{2} \mathrm{OAr}_{m}{ }^{+}$provides a lower limit for the branching ratio of the reactive channel $\left(\mathrm{N}_{2}\right.$ loss $)$, as a fraction of the total loss, of approximately $0.1,0.15$, and 0.4 for $v_{1}, v_{2}$, and $v_{3}$, respectively (see details in the Supporting Information). That $v_{3}$ is more effective in promoting the $\mathrm{N}_{2}$ loss surface chemistry probably reflects the increased energy per photon absorbed.

It is important to note the distinction between this radiation driven chemistry and photoinitiated chemistry observed in smaller metalcontaining clusters such as the mode selective chemistry in $\left[\mathrm{VCO}_{2}\right]^{+}$ in which the reactive vs dissociative branching ratio can be tuned by selectively pumping individual $\mathrm{CO}_{2}$ vibrational modes. ${ }^{12}$ The reaction observed here appears to be essentially thermally driven with the surface bound $\mathrm{N}_{2} \mathrm{O}$ molecule acting as an appropriate chromophore via which to raise the internal energy of the cluster. In this sense the reaction reported here represents a cluster analogue of the temperature programmed desorption technique applied to extended surfaces. Precedent for $\mathrm{N}_{2} \mathrm{O}$ acting in this manner may be found in studies demonstrating infrared resonant desorption of physisorbed $\mathrm{N}_{2} \mathrm{O}$ from the $\mathrm{NaCl}(100)$ surface. ${ }^{13}$

This surface chemistry is not limited to the $n=6$ cluster highlighted here but is observed unambiguously for $n=4,6-8$, almost every cluster size with appreciable signal intensity in our study.

A full analysis of the branching ratios for the various product channels, as a function of both metal cluster size as well as the $\mathrm{N}_{2} \mathrm{O}$ vibrational mode being excited, is underway and will be published in due course. Likewise, a comprehensive computational study of this surface chemistry is also being performed.

Acknowledgment. We gratefully acknowledge the support of the Stichting voor Fundamenteel Onderzoek der Materie (FOM) for providing beam time on FELIX. The authors thank the FELIX staff for their skillful assistance, in particular Dr. B. Redlich and Dr. A.F.G. van der Meer. We are grateful to Dr. D.M. Rayner for providing the rhodium rod and for insightful discussions of our results. W.S.H. is grateful to the Ramsay Memorial Fellowships Trust for his Fellowship. This work was funded by EPSRC under Grants EP/C012070 and EP/C01202X and supported by the Cluster of Excellence "Unifying Concepts in Catalysis" coordinated by the Technische Universität Berlin and funded by the Deutsche Forschungsgemeinschaft.

Supporting Information Available: Computational details and results, comparison with experimental data, data analysis. This material is available free of charge via the Internet at http://pubs.acs.org.

\section{References}

(1) (a) Rayner, D. M.; Lian, L.; Fournier, R.; Mitchell, S. A.; Hackett, P. A. Phys. Rev. Lett. 1995, 74, 2070-2073. (b) Knickelbein, M. B.; Koretsky, G. M. J. Phys. Chem. A 1998, 102, 580-586. (c) Simard, B.; Denommee, S.; Rayner, D. M.; van Heijnsbergen, D.; Meijer, G.; von Helden, G. Chem. Phys. Lett. 2002, 357, 195-203. (d) Fielicke, A.; von Helden, G.; Meijer, G.; Pedersen, D. B.; Simard, B.; Rayner, D. M. J. Am. Chem. Soc. 2005, 127, 8416-8423. (e) Fielicke, A.; Gruene, P.; Meijer, G.; Rayner, D. M. Surf. Sci. 2009, 603, 1427-1433. (f) Fielicke, A.; von Helden, G.; Meijer, G.; Simard, B.; Denommee, S.; Rayner, D. M. J. Am. Chem. Soc. 2003, 125, 11184-11185.

(2) (a) Fielicke, A.; Meijer, G.; von Helden, G. J. Am. Chem. Soc. 2003, 125, 3659-3667. (b) Fielicke, A.; Meijer, G.; von Helden, G. Eur. Phys. J. D 2003, 24, 69-72. (c) Asmis, K. R.; Sauer, J. Mass Spectrom. Rev. 2007, $26,542-562$.

(3) (a) Gregoire, G.; Duncan, M. A. J. Chem. Phys. 2002, 117, 2120-2130. (b) Okumura, M.; Yeh, L. I.; Myers, J. D.; Lee, Y. T. J. Chem. Phys. 1986, $85,2328-2329$.

(4) Fielicke, A.; Kirilyuk, A.; Ratsch, C.; Behler, J.; Scheffler, M.; von Helden, G.; Meijer, G. Phys. Rev. Lett. 2004, 93, 023401.

(5) (a) Fielicke, A.; Ratsch, C.; von Helden, G.; Meijer, G. J. Chem. Phys. 2007, 127, 234306. (b) Gruene, P.; Rayner, D. M.; Redlich, B.; van der Meer, A. F. G.; Lyon, J. T.; Meijer, G.; Fielicke, A. Science 2008, 321, 674-676.

(6) Teffo, J. L.; Chedin, A. J. Mol. Spectrosc. 1989, 135, 389-409.

(7) (a) Zeigarnik, A. V. Kinet. Catal. 2003, 44, 233-246. (b) Liu, S. W.; Horino, H.; Kokalj, A.; Rzeznicka, I.; Imamura, K.; Ma, Y. S.; Kobal, I.; Ohno, Y.; Hiratsuka, A.; Matsushima, T. J. Phys. Chem. B 2004, 108, 38283834.

(8) Harding, D.; Ford, M. S.; Walsh, T. R.; Mackenzie, S. R. Phys. Chem. Chem. Phys. 2007, 9, 2130-2136.

(9) Haq, S.; Hodgson, A. Surf. Sci. 2000, 463, 1-10.

(10) (a) Avery, N. R. Surf. Sci. 1983, 131, 501-510. (b) Madey, T. E.; Avery, N. R.; Anton, A. B.; Toby, B. H.; Weinberg, W. H. J. Vac. Sci. Technol., A 1983, 1, 1220-1221.

(11) Jiang, L.; Xu, Q. A. J. Phys. Chem. A 2009, 113, 5620-5624.

(12) (a) Lessen, D. E.; Asher, R. L.; Brucat, P. J. J. Chem. Phys. 1991, 95, 1414-1416. (b) Citir, M.; Metz, R. B. J. Chem. Phys. 2008, 128, 024307. (c) Citir, M.; Altinay, G.; Metz, R. B. J. Phys. Chem. A 2006, 110, 50515057.

(13) Redlich, B.; Zacharias, H.; Meijer, G.; von Helden, G. Surf. Sci. 2002, 502-503, 325-330.

JA907496C 